\title{
openheart The cardiometabolic consequences of replacing saturated fats with carbohydrates or $\Omega-6$ polyunsaturated fats: Do the dietary guidelines have it wrong?
}

\author{
James J DiNicolantonio
}

To cite: DiNicolantonio JJ. The cardiometabolic consequences of replacing saturated fats with carbohydrates or $\Omega-6$ polyunsaturated fats: Do the dietary guidelines have it wrong?. Open Heart 2014;1:e00032. doi:10.1136/openhrt-2013000032

Accepted 7 January 2014

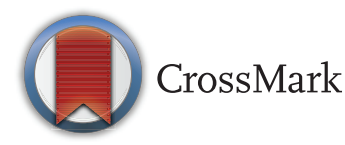

Cardiovascular research scientist and doctor of pharmacy, Ithaca, New York, USA

Correspondence to Dr James J DiNicolantonio; jjdinicol@gmail.com

\section{INTRODUCTION}

A recent publication by Malhotra ${ }^{1}$ was refreshing, inspiring and hit on an important topic that has been heavily debated for over 50 years, that is, are saturated fats as bad as we have been led to believe?

\section{HISTORY OF THE LOW-FAT 'DIET-HEART' HYPOTHESIS}

The vilification of saturated fat by Keys ${ }^{2}$ began two decades before the seven countries study, where Keys showed a curvilinear association between fat calories as a percentage of total calories and death from degenerative heart disease from six countries. However, he excluded data from 16 countries that did not fit his hypothesis. Indeed, data were available at the time from 22 countries, and when all countries were looked at the association was greatly diminished. ${ }^{3}$ Furthermore, no association existed between dietary fat and mortality from all causes of death. ${ }^{3}$ Thus, past data promoted by Keys showing that an increased percentage of fat calories consumed increases the risk of death are not valid (and certainly could never have proved causation). These data seemingly lead us down the wrong "dietary-road" for decades to follow, as pointed out by others. $^{45}$

\section{THE CONSEQUENCES OF REPLACING}

\section{SATURATED FATS WITH CARBOHYDRATES}

The initial Dietary Goals for Americans, published in 1977, proposed increasing carbohydrates and decreasing saturated fat and cholesterol in the diet. ${ }^{6} 7$ This stemmed from the belief that since saturated fats increase total cholesterol (a flawed theory to begin with) they must increase the risk of heart disease. Moreover, it was believed that since fat is the most "calorie-dense" of the macronutrients, a reduction in its consumption would lead to a reduction in calories and a subsequent decrease in the incidence of obesity, as well as diabetes and the metabolic syndrome. However, the advice to increase carbohydrate intake seemingly made things worse, with an increase in its consumption (mainly corn syrup) paralleling the increased incidence of diabetes and obesity in the USA. $^{8}$ In this analysis, fat was not associated with type 2 diabetes when total energy intake was accounted for, ${ }^{8}$ and the intake of saturated fat in the USA during this time was also not on the rise. ${ }^{9}$ These data provide a strong argument that the increase in the consumption of refined carbohydrates was the causative dietary factor for the diabetes and obesity epidemic in the USA.

These data are further strengthened by a randomised, controlled, dietary intervention trial comparing a low-fat $(<10 \%$ saturated fat $)$ versus a low-carbohydrate $(12 \%$ of total calories from carbohydrates) diet. ${ }^{10}{ }^{11}$ While both diets were low in calories $(1500 \mathrm{kcal} /$ day), the low-carbohydrate diet showed greater improvements on numerous endpoints such as (1) body fatness (abdominal fat, body mass), (2) lipids (triglycerides, apolipoprotein B (ApoB)), (3) glucose tolerance (glucose, insulin and insulin resistance-measured via homoeostasis model assessment), (4) inflammation (tumour necrosis factor $\alpha$, interleukin (IL) 6, IL-8, monocyte chemotactic protein 1, E-selectin, intercellular adhesion molecule 1) and (5) thrombogenic markers (plasminogen activator inhibitor 1 ). ${ }^{10}{ }^{11}$ Additionally, the low-carbohydrate diet provided (1) an increase in high-density lipoprotein cholesterol (HDL-C), (2) a reduction 
in the ApoB/ApoA-1 ratio and (3) a reduction in small, dense low-density lipoprotein (sdLDL), whereas all of these parameters were worsened on a low-fat diet. ${ }^{10} 11$ Thus, overall cardiometabolic health seems to improve to a greater extent when carbohydrate is restricted rather than fat.

The assumption that a low-fat diet reduces the 'bad' cholesterol (ie, LDL) is an imprecise notion. While total LDL may be lowered with a reduced intake of dietary fat, if replaced with carbohydrate, this may increase sdLDL particles (ie, pattern B), ${ }^{10}{ }^{11}$ which are more atherogenic than large buoyant LDL particles (ie, pattern A). ${ }^{12}$ Additionally, data indicate that a high saturated fat intake lowers sdLDL particles and raises large buoyant LDL particles. ${ }^{13}$ Thus, replacing carbohydrate with fat may improve the LDL particle size distribution (eg, pattern B shifted to pattern A). Lastly, if fat is replaced with carbohydrate, this may worsen the overall lipid profile (decrease in HDL-C, increase in triglycerides and increase in sdLDL particles)..$^{11}$

Several other randomised trials indicate that a lowcarbohydrate diet reduces weight and improves lipids more than a low-fat diet. ${ }^{14-18}$ Thus, reducing carbohydrates, as opposed to fat, seems to have more favourable effects on atherogenic dyslipidaemia, inflammation, thrombogenic and atherosclerotic surrogate markers. ${ }^{10-18}$ From these data, it is easy to comprehend that the global epidemic of atherosclerosis, heart disease, diabetes, obesity and the metabolic syndrome is being driven by a diet high in carbohydrate/sugar as opposed to fat, a revelation that we are just starting to accept.

\section{THE CONSEQUENCES OF REPLACING SATURATED FATS WITH POLYUNSATURATED ( $\Omega-6)$ FATS}

Not only has the condemnation of saturated fats led to an increased consumption of carbohydrates, it has also led to several dietary guidelines recommending replacement of saturated fats with polyunsaturated fats, without specifying which polyunsaturated fatty acid (ie, $\Omega-3$ vs $\Omega-6)$. The recommendation for increasing polyunsaturated fat stems from pooled analyses of data looking at increasing $\Omega-3$ and $\Omega-6$ polyunsaturated fatty acids. ${ }^{19} 20$ However, a meta-analysis of randomised controlled trials showed that replacing a combination of trans-fats and saturated fats with $\Omega-6$ polyunsaturated fats (without simultaneously increasing $\Omega-3$ fatty acids) leads to an increased risk of death. ${ }^{21}$ These results were corroborated when data were recovered from the Sydney Diet Heart Study and included in an updated meta-analysis. ${ }^{22}$

Other human trials, not included in the aforementioned meta-analysis, include the Anti-Coronary Club trial, which showed that more people died (overall (26 vs 6 ) and due to coronary heart disease ( 8 vs 0$)$ ) when saturated fat was replaced with polyunsatured fat. ${ }^{23}$ The National Diet Heart Trial, a randomised, double-blind study, also showed a higher number of cardiovascular events $(n=4)$ on a diet that was high in the polyunsaturated $(\mathrm{P}) /$ saturated $(\mathrm{S})$ fat ratio $(2: 1)$, than on a diet high in saturated fat $(\mathrm{n}=1, \mathrm{P} / \mathrm{S}=0.4) .{ }^{24}$ Thus, advice to replace saturated fats with polyunsaturated fats (ie, $\Omega-6$ ) may increase the risk of coronary heart disease, cardiovascular events, death due to coronary heart disease and overall mortality. ${ }^{21-24}$

Reasons for the potential harmful effects of $\Omega-6$ fatty acids may be due to their promotion of cancer, suppression of the immune system, lowering of HDL-C and increasing the susceptibility of LDL to oxidation. ${ }^{25}$ Further evidence indicates a role of $\Omega-6$ in promoting prostate $^{26-28}$ and breast cancer. ${ }^{29}$ This is supported by the Anti-Coronary Club study, where there was $71 \%$ increased risk of death from causes other than coronary heart disease among individuals who were placed on a diet designed to increase the $\mathrm{P} / \mathrm{S}$ ratio in those who had not experienced a new coronary event. ${ }^{30}$ Moreover, in a controlled clinical trial by Dayton et al, ${ }^{31}$ there was a greater than threefold increased risk of death due to carcinoma when saturated fat (mainly of animal origin) was substituted for $\Omega-6$ polyunsaturated fat (including corn, soybean, safflower and cottonseed). The potential harms of replacing saturated fat with carbohydrates or $\Omega-6$ polyunsaturated fats are summarised in box 1 .

\section{LACK OF EVIDENCE FOR A LOW-FAT DIET}

Data are lacking in the support of a low-fat diet. In the low-fat diet in myocardial infarction trial, a controlled trial was performed to test if a low-fat diet would improve outcomes in 264 men who had recently recovered from a first myocardial infarction. ${ }^{32}$ Despite the fact that patients in the low-fat diet group ate significantly less fat ( $45 \mathrm{~g}$ / day vs $110-130 \mathrm{~g} /$ day), consumed less calories (approximately 1950 calories vs 2450 calories), obtained a lower cholesterol level and achieved a greater fall in body weight than those in the control group, there was no difference in definite reinfarction or death.

Box 1 The potential harms of replacing saturated fat with carbohydrates or $\Omega-6$ polyunsaturated fats

The potential harms of replacing saturated fat with carbohydrates Increase in small, dense LDL particles.

- Shift to an overall atherogenic lipid profile (lower HDL-C, increase in triglycerides and an increase in the $\mathrm{ApoB} / \mathrm{ApoA}$ 1 ratio).

- Smaller improvements in glucose tolerance, body fatness, weight, inflammation and thrombogenic markers.

- Increased incidence of diabetes and obesity.

The potential harms of replacing saturated fat with omega- 6 polyunsaturated fats

- Increased risk of cancer.

- Increased risk of coronary heart disease, cardiovascular events, death due to heart disease and overall mortality.

> Increased oxidised LDL-C.

Reduction in HDL-C. 
In the Women's Health Initiative (WHI), a randomised controlled trial including 48835 postmenopausal women, a low-fat diet was not shown to reduce coronary heart disease, stroke or cardiovascular disease, ${ }^{33}$ despite a significant reduction in LDL-C, nor was there a reduction in cancer. ${ }^{34}{ }^{35} \mathrm{~A}$ meta-analysis by Siri-tarino et $a l^{6}$ consisting of 21 prospective epidemiological studies, derived from 347747 participants, indicated that the intake of saturated fat does not increase coronary heart disease or cardiovascular disease. Moreover, a recent Cochrane meta-analysis indicated that changing dietary fat intake does not affect total mortality or cardiovascular mortality. ${ }^{37}$ Although reducing saturated fat was associated with a reduced risk of cardiovascular events by $14 \%$, this was not shown with reducing total fat consumption. ${ }^{37}$ While the WHI study and the Siri-tarino and Cochrane meta-analyses cannot be taken at face value, taken together with "the low-fat diet in myocardial infarction trial", a compelling argument can be made for the general lack of evidence in support of a low-fat diet. Dietary recommendations based on evidence from the literature are summarised in box 2 .

The final nail in the low-fat diet coffin is two randomised trials, one for the primary prevention of cardiovascular disease, PREDIMED ${ }^{38}$ (Prevención con Dieta Mediterránea), indicating a reduction in the incidence of major cardiovascular events with a Mediterranean diet compared with a low-fat diet, and the other for the secondary prevention of cardiovascular disease, the Lyon Diet Heart Study ${ }^{39}$ showing that a Mediterranean diet reduces all-cause and cardiovascular mortality as well as non-fatal myocardial infarction compared with a prudent diet.

\section{CONCLUSIONS}

In summary, the benefits of a low-fat diet (particularly a diet replacing saturated fats with carbohydrates or $\Omega-6$

Box 2 Dietary recommendations based on evidence from the literature

Dietary guideline recommendations suggesting the replacement of saturated fat with carbohydrates $/ \Omega-6$ polyunsaturated fats do not reflect the current evidence in the literature.

- A change in these recommendations is drastically needed as public health could be at risk.

- The increase in the prevalence of diabetes and obesity in the USA occurred with an increase in the consumption of carbohydrate not saturated fat.

- There is no conclusive proof that a low-fat diet has any positive effects on health. Indeed, the literature indicates a general lack of any effect (good or bad) from a reduction in fat intake.

- The public fear that saturated fat raises cholesterol is completely unfounded as the low-density lipoprotein particle size distribution is worsened when fat is replaced with carbohydrate.

- A public health campaign is drastically needed to educate on the harms of a diet high in carbohydrate/sugar.

- It would be naive to assume that any recommendations related to carbohydrate or fat intake would apply to processed foods, which undoubtedly should be avoided if possible. polyunsaturated fatty acids) are severely challenged. Dietary guidelines should assess the totality of the evidence and strongly reconsider their recommendations for replacing saturated fats with carbohydrates or $\Omega-6$ polyunsaturated fats.

Competing interests None.

Provenance and peer review Commissioned; internally peer reviewed.

Open Access This is an Open Access article distributed in accordance with the Creative Commons Attribution Non Commercial (CC BY-NC 3.0) license, which permits others to distribute, remix, adapt, build upon this work noncommercially, and license their derivative works on different terms, provided the original work is properly cited and the use is non-commercial. See: http:// creativecommons.org/licenses/by-nc/3.0/

\section{REFERENCES}

1. Malhotra A. Saturated fat is not the major issue. BMJ 2013;347 f6340.

2. Keys A. Atherosclerosis: a problem in newer public health. J Mt Sinai Hosp NY 1953;20:118-39.

3. Yerushalmy J, Hilleboe HE. Fat in the diet and mortality from heart disease. A methodologic note. NY State J Med 1957;57:2343-54.

4. Le Fanu J. The rise and fall of modern medicine. New York: Carroll \& Graf, 1999.

5. Taubes G. The soft science of dietary fat. Science $2001 ; 291: 2536-45$.

6. Hite $\mathrm{AH}$, Feinman RD, Guzman GE, et al. In the face of contradictory evidence: report of the Dietary Guidelines for Americans Committee. Nutrition 2010;26:915-24.

7. Select Committee on Nutrition and Human Needs of the United States Senate. Dietary goals for the United States. 2nd edn. Washington, DC: US Government Printing Office, 1977.

8. Gross LS, Li L, Ford ES, et al. Increased consumption of refined carbohydrates and the epidemic of type 2 diabetes in the United States: an ecologic assessment. Am J Clin Nutr 2004;79:774-9.

9. Hite AH, Feinman RD, Guzman GE, et al. In the face of contradictory evidence: report of the Dietary Guidelines for Americans Committee. Nutrition 2010;26:915-24.

10. Volek JS, Fernandez ML, Feinman RD, et al. Dietary carbohydrate restriction induces a unique metabolic state positively affecting atherogenic dyslipidemia, fatty acid partitioning, and metabolic syndrome. Prog Lipid Res 2008;47:307-18.

11. Forsythe CE, Phinney SD, Fernandez ML, et al. Comparison of low fat and low carbohydrate diets on circulating fatty acid composition and markers of inflammation. Lipids 2008;43:65-77

12. Tribble DL, Holl LG, Wood PD, et al. Variations in oxidative susceptibility among six low density lipoprotein subfractions of differing density and particle size. Atherosclerosis 1992;93:189-99.

13. Dreon DM, Fernstrom $\mathrm{HA}$, Campos $\mathrm{H}$, et al. Change in dietary saturated fat intake is correlated with change in mass of large low-density-lipoprotein particles in men. Am J Clin Nutr 1998;67: 828-36.

14. Foster GD, Wyatt HR, Hill JO, et al. A randomized trial of a low-carbohydrate diet for obesity. N Engl J Med 2003;348:2082-90.

15. Stern L, Iqbal N, Seshadri $P$, et al. The effects of low-carbohydrate versus conventional weight loss diets in severely obese adults: one-year follow-up of a randomized trial. Ann Intern Med 2004;140: 778-85.

16. Gardner C, Kiazand A, Alhassan S, et al. Comparison of the Atkins, Zone, Ornish, and LEARN diets for change in weight and related risk factors among overweight premenopausal women. JAMA 2007;297: 969-77.

17. Yancy WS Jr, Olsen MK, Guyton JR, et al. A low-carbohydrate, ketogenic diet versus a low-fat diet to treat obesity and hyperlipidemia: a randomized, controlled trial. Ann Intern Med 2004;140:769-77.

18. Shai I, Schwarzfuchs D, Henkin $Y$, et al. Dietary Intervention Randomized Controlled Trial (DIRECT) Group. Weight loss with a low-carbohydrate, Mediterranean, or low-fat diet. N Engl J Med 2008;359:229-41.

19. Mozaffarian D, Micha R, Wallace S. Effects on coronary heart disease of increasing polyunsaturated fat in place of saturated fat: a systematic review and meta-analysis of randomized controlled trials. PLoS Med 2010;7:e1000252.

20. Jakobsen MU, O'Reilly EJ, Heitmann BL, et al. Major types of dietary fat and risk of coronary heart disease: a pooled analysis of 11 cohort studies. Am J Clin Nutr 2009;89:1425-32. 
21. Ramsden CE, Hibbeln JR, Majchrzak SF, et al. n-6 fatty acid-specific and mixed polyunsaturate dietary interventions have different effects on CHD risk: a meta-analysis of randomised controlled trials. Br J Nutr 2010;104:1586-600.

22. Ramsden CE, Zamora D, Leelarthaepin B, et al. Use of dietary linoleic acid for secondary prevention of coronary heart disease and death: evaluation of recovered data from the Sydney Diet Heart Study and updated meta-analysis. BMJ 2013;346:e8707.

23. Christakis $\mathrm{G}$, Rinzler $\mathrm{SH}$, Archer $\mathrm{M}$, et al. Effect of the anti-coronary club program on coronary heart disease. Risk-factor status. JAMA 1966;198:597-604.

24. National Diet-Heart Study Report. Dropouts, exclusions, non-cardiovascular and cardiovascular events. Circ 1968;37/38 (Suppl 1):I222-52.

25. Grundy SM. Multifactorial etiology of hypercholesterolemia Implications for prevention of coronary heart disease. Arterioscler Thromb Vasc Biol 1991:11:1619-35.

26. Kelavkar UP, Hutzley J, Dhir R, et al. Prostate tumor growth and recurrence can be modulated by the omega- 6 :omega- 3 ratio in diet: athymic mouse xenograft model simulating radical prostatectomy. Neoplasia 2006;8:112-24.

27. Williams CD, Whitley BM, Hoyo $C$, et al. A high ratio of dietary $n-6 /$ n-3 polyunsaturated fatty acids is associated with increased risk of prostate cancer. Nutr Res 2011;31:1-8.

28. Ritch CR, Wan RL, Stephens LB, et al. Dietary fatty acids correlate with prostate cancer biopsy grade and volume in Jamaican men. J Urol 2007;177:97-101.

29. Murff $\mathrm{HJ}$, Shu XO, Li H, et al. Dietary polyunsaturated fatty acids and breast cancer risk in Chinese women: a prospective cohort study. Int J Cancer 2011;128:1434-41.

30. Christakis G, Rinzler SH, Archer M, et al. The anti-coronary club. A dietary approach to the prevention of coronary heart disease-a seven-year report. Am J Public Health Nations Health 1966;56: 299-314.

31. Dayton S, Pearce ML, Hashimoto S, et al. A controlled clinical trial of a diet high in unsaturated fat in preventing complications of atherosclerosis. Circulation 1969;40(Suppl 2):1-63.

32. [No authors listed]. Low-fat diet in myocardial infarction: a controlled trial. Lancet 1965;2:501-4.

33. Howard BV, Van Horn L, Hsia J, et al. Low-fat dietary pattern and risk of cardiovascular disease the women's health initiative randomized controlled dietary modification trial. JAMA 2006;295: 655-66.

34. Beresford SAA, Johnson KC, Ritenbaugh C, et al. Low-fat dietary pattern and risk of colorectal cancer the women's health initiative randomized controlled dietary modification trial. JAMA 2006;295: 643-54.

35. Prentice RL, Caan B, Chlebowski RT, et al. Low-fat dietary pattern and risk of invasive breast cancer the women's health initiative randomized controlled dietary modification trial. JAMA 2006;295: 629-42.

36. Siri-tarino PW, Sun Q, Hu FB, et al. Meta-analysis of prospective cohort studies evaluating the association of saturated fat with cardiovascular disease. Am J Clin Nutr 2010;91:535-46.

37. Hooper L, Summerbell CD, Thompson R, et al. Reduced or modified dietary fat for preventing cardiovascular disease. Cochrane Database Syst Rev 2011;(7):CD002137.

38. Estruch R, Ros E, Salas-Salvadó J, et al. PREDIMED Study Investigators. Primary prevention of cardiovascular disease with a Mediterranean diet. N Engl J Med 2013;368:1279-90.

39. de Lorgeril M, Salen P, Martin JL, et al. Mediterranean diet, traditional risk factors, and the rate of cardiovascular complications after myocardial infarction: final report of the Lyon Diet Heart Study. Circulation 1999;99:779-85. 